same ship with last case. Sanguine temperament; narrow chest. Has had frequent attacks of hæmoptysis. Mother died of phthisis. Gained flesh and strength on the voyage, and had no spitting of blood since leaving England. Tubercle in left apex, and probably right base. He improved greatly for some months, but subsequently got repeated attacks of congestion and hæmoptysis from too close confinement to business. I strongly urged the propriety of a voyage to the Mauritius or the Cape and back, with a subclavian seton, which would probably have restored him; but this was delayed and put off, till one evening he took a chill, pneumonia ensued, and the lungs broke up rapidly. Under more favourable conditions this case would have continued to improve.

Mr. H. (Case 7), aged thirty. Family history good. Spat blood in March, 1863, when clerk in a bank in London. Phthisical symptoms followed in ordinary course. Arrived in Melbourne Feb. 1865. Physical signs: dulness in left subclavian, with moist tubercular click, audible also behind ; left lung pretty healthy. Has lost about a stone and a half in weight. Improved slightly on the voyage. In April he commenced bank work in Melbourne, which was followed by increased cough and expectoration, with night-sweats. To take cod oil and hypophosphites. Band of gutta-percha seton introduced under left clavicle. April 15th: Much improved; gaining flesh; cough and expectoration have ceased; feels better and stronger than at any time since the commencement of his illness. July 19th: Seton has cut itself out; another introduced; still gaining weight, and in excellent spirits; no morbid sounds audible beyond slight dulness. Sept. 12th : Seton came away. Nov. 10th: Symptoms disposed to return; has spat a little blood; another seton introduced. Jan. 3rd, 1866 : In very good health, in spite of very severe work, his bank being short-handed; appetite excellent; weight about stationary. March 10th: Seton came away. Aug. lst: Has remained well in spite of being terribly overworked, but has lost flesh since the seton came away; takes cod oil and hypophosphites for two or three weeks at a time, with intervals; chest symptoms quiet-should they recur, he will come at once for another seton, feeling the relief it gives him. This is a very instructive case. The patient has been living in Mel. bourne in the same conditions, exaggerated, under which the tuberculous diathesis was induced in London. Had his lot been cast in a country district, inland, with open air employment, I have little doubt that restoration to perfect health would have resulted from the first few months of residence in Australia. As it is, I have every hope that (even with his disadvantageous employment) the lung mischief may be quieted and staved off by judicious counter-irritation till his naturally good constitution has outgrown its acquired tuberculous tendencies. No temporary counter-irritant, such as blisters, iodine, or croton oil, could have produced the permanent good effect of the seton. The smooth gutta-percha band is almost painless after the first couple of days, and so far from weakening the patient (in properly selected cases), he usually, as in this case, steadily gains in weight and strength when it is in, and loses when it comes away. That the habit can be over. come as the need for it diminishes is seen from the increased interval of immunity from chest symptoms between each suc. cessive seton.

Cases $3,20,31$, and 34 are specimens of a class of which I might have introduced a great number-viz., persons who left Fngland many years ago with all the symptoms of phthisis, and not only recovered in this country but remained well up to the present time. However, to avoid fallacy, to which such histories are very open, I have preferred to notice these four only, in which, from the flattening and altered movements of the chest, former hæmoptysis, and (in three of the four) strong hereditary predisposition to phthisis, there can be no doubt that this disease formerly had obtained a decided hold upon the patient.

It will be remarked that the voyage and residence in this slimate failed entirely to do any good in some of the cases of advanced phthisis mentioned, while others equally unpromising were restored to comparative or complete health. I can give no rule as yet for the selection of proper or improper cases beyond the well-ascertained fact that the sea voyage, almost withont exception, benefits those cases of phthisis which are characterised by a tendency to actice congestion and hamoptusis.

In cases 9, 21, and 27 I have little doubt that unfavourable mental ininences were at work.

Patients arriving here sometimes manifest great disappointment that the climate does not come up to their idea of perfection on first landing, quite forgetting that a perfect climate on our planet is an impossibility. A place which enjoys winters: of tropical mildness must of necessity suffer summers of tropical heat, and vice vers $\hat{a}$. The advantages which the southern littoral of Victoria enjoys above any other country in the civilised world are-greater uniformity of temperature during the year, combined with a tonic, stimulating air. Although some few days of summer are excessively hot, the averarfe summer heat in Melbourne is only three or four degrees above that of London, while the winter cold is much more than correspondingly less, being exactly the average spring tem. perature of London. Patients who have leisure and money enough to study their health may, by changing their locality according to season, in a few hours, by rail or steam, obtain a climate as near as possible perfection all the year round. Some of my patients spend spring and autumn in Melbourne, summer in the highlands of Tasmania, and winter, which is barely ten weeks in duration, on the plains of the Murray or Darling. By this means they enjoy a bright, clondless, invi. gorating climate of a mild temperature all the year.

Elizabeth-street, Melbourne, Sept. 1866.

\section{ON THE TREATMENT OF CHOLERA BY STRYCHNINE.}

\section{By GEORGE W. BALFOUR, M.D.}

WhATEVER tends to increase our capability of coping with so formidable a disease as cholera cannot be uninteresting to the profession at any time, but must be specially interesting at the present moment, when we are still labouring under an epidemic most severe in its character, if not, as yet, very widespread in its dimensions.

The bromides of potassium and ammonium, the chlorate of potass, and the saturated tincture of camphor, have all been tried without any marked success, and have left only the impression that as yet no advance has been made on former. plans, and that the best treatment for cholera is still a large dose of opium early enough; and God help those who pass into the stage of complete collapse, for then all human remedies seem alike useless. The treatment, however, which 1 am about to recommend may be used with great hope of success even in cases of the most complete collapse, and, even where not successful, it relieves the most painful symptomsthe cramps, - and remedies all the worst features of the disease. It is, however, no new and hitherto untried remedy, for it was long ago recommended by $M$. Abeille, who states that it modifies advantageously and rapidly the phenomena of cholera by its influence on the sensitive nerres. In the alcide stage it excited reaction nineteen times out of twenty-three cases, and there were ten recoveries.

Though long lost sight of in this country, strychnine was employed with marked success during a comparatively recent outbreak of cholera in Japan by Assist. -surgeon W. Hensman. of the second battalion of the 20th Regt.; and the attention of my brother, John Balfour, I.G., having been directed to it, he resolved to give it a fair trial in an ontbreak of cholera at Leven, Fifeshire, where he is now in charge. He writes me that he has seen nothing which so speedily relieves the urgent symptoms, or gives such hope of snatching many a serious case from the verge of the grave. The cramps soon cease, the purging and vomiting are nitigated, and in those cases in which the pulse has been imperceptible for hours, it is again felt at the wrist, while the complexion changes from the horrible dull-blue tint to the natural healthy colour, the urine being also generally secreted at once. The urgent symptoms are, in fact, immediately relieved, and though it does not cure every case, this treatment holds out a fair prospect of more favourable returns under circumstances more propitious than could be supplied in a small country town of 2700 inhabitants, with one medical practitioner to attend upon all the cholera patients, no hospital, and a defective supply of nurses. As it is, 15 out of 24 well-marked cases thus treated have died; but many of them would have succumbed under all cireumstances. even to a disease less formidable than cholera, as three werw between seventy and eighty years of age, two more above sixty, another had long-standing disease buth of the chest and womb, and several others were greatly deficient in bodily strength and stamina. 
The general plan of treatment adopted is to place hot bottles cound the patient and cover him with an ample supply of blankets; a large sinapism is then applied over the whole abdomen, and, in adults, left on for an hour. If the disease be not too far advanced, a drachm of laudanum is then administered (chlorodyne was employed at first, but was found too irritating to the stomach), ice to suck is allowed ad libitum, and small quantities of soda water if desired. Should this treatment have a good effect, the patient is conducted to recovery in the ordinary way; but should vomiting recur, or collapse come on, strychnine is had recourse to, a solution being employed containing one grain to the ounce, and of this a drachm and a half to two drachms is given to an adult for the first dose, and subsequently a drachm every hour and a half or two hours, until the physiological effects of the drug (twitching of the muscles) manifest themselves; these are always accompanied by marked amendment. The subsequent treatment hitherto adopted has been the administration of yuinine and nourishing soups in small but increasing quantities. It is believed, however, that the continuance of the strychnine in smaller doses and at longer intervals would be more beneficial in the more dangerous and severe cases. As it is, complete recovery has taken place in many patients in whom the symptoms had been of the most deadly character, the pulse having been in some of them more than four hours absent from the wrist; and in them no stimulants were administered, at least until convalescence bad fairly set in.

The type of the disease at Leven has been of the very worst character, attended by comparatively little vomiting and purging; as a rule, the cramps not severe; but the patient struck down and sinking as from some overwhelming dose of poison.

The treatment of cholera by strychnine, then, seems to hold out a fairer prospect of success than anything hitherto tried, while it promises two great and eminent advantages: lst, even where it does not cure, it always relieves the symptoms; and, 2nd, though useful even in the most advanced stages of the disease, its action is not interfered with, but rather assisted by the previous administration of opium, which the united experience of, I believe, almost all those medical men who have had any experience of the disease has shown to be the most useful remedy in the earlier stages of cholera; for the researches of Brown-Séquard, Bonnefin, and others have shown that morphia and opium act on the spinal cord preeisely as strychnine does, and, when administered together, one-half of the ordinary dose of strychnine is sufficient to produce the same effects as double the quantity administered without opium. Were $I$ to nazard a theory as to the modus operandi of strychnine in cholera, it should be based on this correlation subsisting between it and opium, and I would say that as all the symptoms of cholera collapse point to a cessation of all the acts of vital nutrition, and consequently of the circulation, throughout the frame, wholly independent of drainage by evacuation, and often most marked where there are no evacuations, depending apparently in such cases upon the charge of poison being sufficient at once to overwhelm the nervous system, and thus prevent that reflex action of the sympathetic and cerebro-spinal systems on each other upon which, according to all our present knowledge, these vital acts seem to depend, so then our best hope of cure would appear to lie in some drug which should so stimulate the cerebrospinal system as to enable it to respond to the feeble efforts which the sympathetic must continue to exert while life remains. In the earlier stages of cholera, and in less severe cases, opium, from its stimulant action on the cerebro-spinal system, is well calculated to attain this end, while its astringent action is rather an advantage in those cases in which the drainage from evacuation tends to be excessive; the hypothetical benefits of elimination being at variance with our practical knowledge of this disease, and manifestly inconsistent with the theory of zymosis and with all that we know of the history of diseases of this class. In more advanced or more severe cases, strychnine, the most powerful cerebro-spinal stimulant known, seems theoretically that agent most likely to be useful, and I think that the facts I have just related warrant my recommending it to my professional brethren as likely under favourable circumstances even to exceed their highest expectations.

Lynedoch-place, Edinburgh, Dec. 1866.

The Hunterian Oration.-Prof. Hilton, F.R.S., will deliver the biennial oration in memory of John Hunter on Thursday, February 14th. The annual courses of lectures by Professors Huxley and Hancock will follow.

\section{A}

OF THE PRACTICE OF

\section{MEDICINE AND SURGERY} IN THE

\section{HOSPITALS OF LONDON.}

Nulla autem est alia pro certo noscendi via, nisi quamplurimas et morborum se comparare.-MongaeNI De Sed. et Caus. Morb., lib. iv. Procmium.

\section{GUY'S HOSPITAL.}

\section{A CASE OF PROGRESSIVE MUSCULAR ATROPHY FROM LEAD-POISONING.}

(Under the care of Dr. WILKs.)

THE patient whose case is here related is still an inmate of the hospital. Her improvement, however, has been so steady and marked for some time past that there can be no object in delaying the publication of her case, which is one of peculiar interest. It chanced that we saw her whilst she was being admitted into the hospital, and the change which is now to be observed in her appearance is indeed remarkable. Our account of the case is partly derived from notes taken by Mr. Branford Edwards, Dr. Wilks's clinical clerk, and partly from our own observation.

Amelia $\mathrm{C}-$ - aged twenty-four, single, admitted on the 4th of July, 1866, in a state of extreme emaciation. She lies on her back, perfectly helpless, and presenting literally the appearance of a skeleton. Every muscle in the body is wasted to a very unusual and remarkable extent. Those of the back share in the general atrophy, which, however, is perhaps most of all marked in the muscles of the hands and arms. The fingers are flexed, giving the characteristic "griffin's claw" appearance, the flexion being of the phalangeal and not the metacarpo-phalangeal joints. The interossei seem to have entirely disappeared, so that the finger and thumb of an observer can be made to meet between the metacarpal bones. The radius and ulna can be made out throughout their length quite as dis tinctly as though covered only by integument The legs and feet are in a very similar condition. So wasted are the abdo minal muscles that the spine can be distinctly felt throughout the lumbar region.

Her history is mainly derived from herself, and is not quite so clear as might be wished. It seems, however, that she began to menstruate at fourteen, and at that time was particularly fat. She lived at home with her parents, assisting in the household work, and, although not very strong, enjoying very fair health. About five years ago she would appear to have sustained a great mental shock from the death of her mother. She went on a visit to London, and there suffered from what she calls " inflammation of the bowels," which laid her up for two months. She has never been so well, she thinks, since that attack; but she was able to get about and work as usual. Her condition was one of debility, with irregular menstruation and slight hysteria. In November, 1864, she entirely ceased menstruating. In February, 1865, she left her home, owing to her father marrying again, giving up his farm, and taking a situation. She seems to have fretted very much at these changes and at her failing health. For nights together, she says, she did not sleep, thinking of her troubles. She got weaker, and lost her appetite. At this time (seventeen months before admission) she went to stay with a sister living at a village in Kent. Soon after her arrival (we learn from the doctor who attended her) she suffered more than once from attacks of hysteria; and she had not been' in the house more than six or seven weeks when her health became worse than ever. She suffered from constant vomiting, abdominsl pain and gradually increasing weakness in her extremities, which she first noticed, she thinks, in her hands and arms. She lost all power over her limbs, and lay helpless in bed. In July, 1865, she lost her voice for about eight weeks, at the end of which time it returned. From this time she never left her bed for a year. At first there was great constipation of the bowels, sometimes no action taking place for a month. This was succeeded after some months by diarrhcea, and she often 